\title{
Clinical application of High-flow nasal cannula oxygen therapy in acute heart failure
}

\author{
Xiong LIU ${ }^{1,2}$, Rong WU ${ }^{1,2}$, Liren $\mathrm{LAI}^{1,2}$, Jiyan $\operatorname{LIN}^{1,2, *}$ (D)
}

\begin{abstract}
The High-flow nasal cannula (HFNC) oxygen therapy has received attention as an alternative to respiratory support in critically ill patients. It gives you a continuous flow of fresh gas at high flow rates replacing or washing out the patient's pharyngeal deadspace. Every breath that the patient now breathes will be cleared of carbon dioxide and replaced with an oxygen-rich gas, which improves breathing efficiency. Although the use of HFNC in adults who are critically ill has been dramatically increasing, the advantages and disadvantages of each element have not been well discussed. Although the use of HFNC in critically ill adults has increased dramatically, its advantages and disadvantages have not been well discussed. The pathophysiological mechanism of AHF caused by dyspnea and hypoxia is different from the primary respiratory disease, the indications, timing and efficacy of HFNC in AHF treatment are not satisfactory. This paper reviews related research in recent years to improve the AHF respiratory support level with reasonable use of HFNC.
\end{abstract}

Keywords: high-flow nasal cannula, respiratory support, pathophysiology, acute heart failure.

Practical Application: HFNC has a unique advantage in the treatment of AHF with hypoxemia due to the ability to produce a certain level of PEEP, providing humidified warming and stable oxygen concentration and oxygen flow, reducing respiratory work and comfort. This paper reviews related research in recent years to improve the AHF respiratory support level with reasonable use of HFNC.

\section{Introduction}

Dyspnea and hypoxia are the most common symptoms of acute heart failure (AHF) and are the leading cause of emergency care (Gheorghiade \& Pang, 2009); respiratory support is the first measure taken during AHF emergency treatment (Mebazaa et al., 2015). HFNC is a new type of respiratory support developed in recent years. HFNC devices allow modification of only two variables - the percentage of oxygen being delivered and the rate of gas flow. There are at this time only two such devices on the market. Both are capable of delivering a mix of air and oxygen with an inspired oxygen fraction $\left(\mathrm{FiO}_{2}\right)$ ranging between 0.21-1.0. HFNC can partially substitute non-invasive ventilator function, and has higher humidification efficiency and better comfort. It has been proposed that the HFNC can provide several benefits. Among these are maintenance of a constant $\mathrm{FiO}_{2}$, generation of a positive end-expiratory pressure (PEEP), reduction of the anatomical dead space, improvement of mucociliary clearance and reduction in the work of breathing. Therefore, its clinical application is also more and more extensive.

The HFNC is very versatile and user friendly. It can be used in a low-monitoring environment, with almost no knowledge of mechanical ventilation. However, most patients treated with the HFNC are extremely hypoxemic, which raises important questions regarding whether it should be used in such conditions. Regardless of this controversy, several potential clinical uses for the HFNC have emerged in recent years. Among these are included the respiratory support of patients with acute hypoxemic respiratory failure or respiratory distress syndrome (ARDS), with respiratory compromise induced by heart failure and with respiratory compromise post-extubation.

\section{Clinical mechanism of nasal high-flow oxygen therapy}

HFNC oxygen therapy is increasingly used as part of both ward-based and critical care management of respiratory failure. Respiratory failure is distressing for patients and treatment modalities currently in use may be associated with discomfort from upper airway drying, tightly fitting facemasks, and resultant complications such as skin breakdown. Invasive ventilation is also associated with a number of complications including ventilator-associated pneumonia. HFNC provide positive pressure to the airways was first noted in neonates, and it is in this patient group that this therapeutic effect was first used. A similar continuous positive airway pressure (CPAP) effect, with higher flows, was noted in adults1 and from here, HFNC oxygen therapy was developed (Figure 1) (Gotera et al., 2013).

\subsection{HFNC produces a low level of positive end expiratory pressure (PEEP) effect}

The inspiratory flow rate (IFR) demanded by a person under normal breathing conditions is $30 \sim 40 \mathrm{~L} / \mathrm{min}$, but the IFR required by the patient in dyspnea or respiratory failure is greater than $70 \mathrm{~L} / \mathrm{min}$ (Anderson et al., 2006); therefore, when 
the normal oxygen inhalation mode cannot meet the oxygen flow requirements of patients with respiratory failure, the patient's inhaled oxygen is mixed into the indoor air, which significantly reduce the concentration of oxygen inhaled by critically ill patients by using of traditional oxygen inhalation (nasal catheter or mask oxygen). The volume fraction usually does not reach the set indicator. The IFR achieved by HFNC can match the oxygen flow requirement of patients with respiratory failure, so that the volume fraction of inhaled oxygen is constant and reaches the patient's requirement (up to $90 \%$ of the volume fraction of inhaled oxygen can be achieved) (Masclans \& Roca, 2012).

HFNC refers to a high-flow $(8-80 \mathrm{~L} / \mathrm{min})$ inhalation that provides a patient with a regulated and relatively constant oxygen concentration $(21 \%$ to $100 \%)$, temperature $\left(31-37{ }^{\circ} \mathrm{C}\right)$, and humidity through a high-flow nasal plug. The device is mainly composed of an air oxygen-mixing device, a humidification therapy device, a high-flow nasal plug and a connecting breathing tube, and generates a certain level of PEEP by delivering a high-flow gas to maintain the alveolar opening. Groves et al (Groves \& Tobin, 2007) compared airway pressure changes in 10 healthy subjects under different oxygen flow and respiratory conditions. It was found that subjects who used HFNC had a significant increase in expiratory airway pressure $(\mathrm{P}<0.001)$, positively correlated with oxygen flow, regardless of the mouth opening and closing state. Under closed breathing conditions, the expiratory airway pressure can be increased by about $0.8 \mathrm{cmH}_{2} \mathrm{O}$ for every $10 \mathrm{~L} / \mathrm{min}$ of oxygen flow. The value of airway pressure is also affected by factors such as height and gender. In the same situation, women have higher airway pressure than men. Parke et al (Parke et al., 2009) also observed in 15 patients after cardiac surgery, a ratio of $35 \mathrm{~L} / \mathrm{min}$, close mouth breathing can produce a higher level of positive airway pressure than opened mouth breathing [ 2.7 (1.04) vs $1.2(0.76)$ $\left.\mathrm{cmH}_{2} \mathrm{O}\right](\mathrm{P}=0.001)$, they all have a significant increase over traditional oxygen therapy. Corley et al (Corley et al., 2011) confirmed that HFNC could partially recapture the alveoli in patients with acute respiratory failure after cardiac surgery, thus improving the patient's oxygenation level.

\subsection{HFNC maintains stable volume fraction and flow of inhaled oxygen}

AHF causes pulmonary congestion and edema. At this time, the patient has acute dyspnea/hypoxia/compensatory, which causes the respiratory deepening to accelerate, and the patient's IFR increases significantly. Studies have shown that patients with acute hypoxia can have a peak inspiratory flow of 30 to $120 \mathrm{~L} / \mathrm{min}$, while conventional oxygen therapy can only provide a flow rate of up to $15 \mathrm{~L} / \mathrm{min}$, which not only fails to meet the needs of

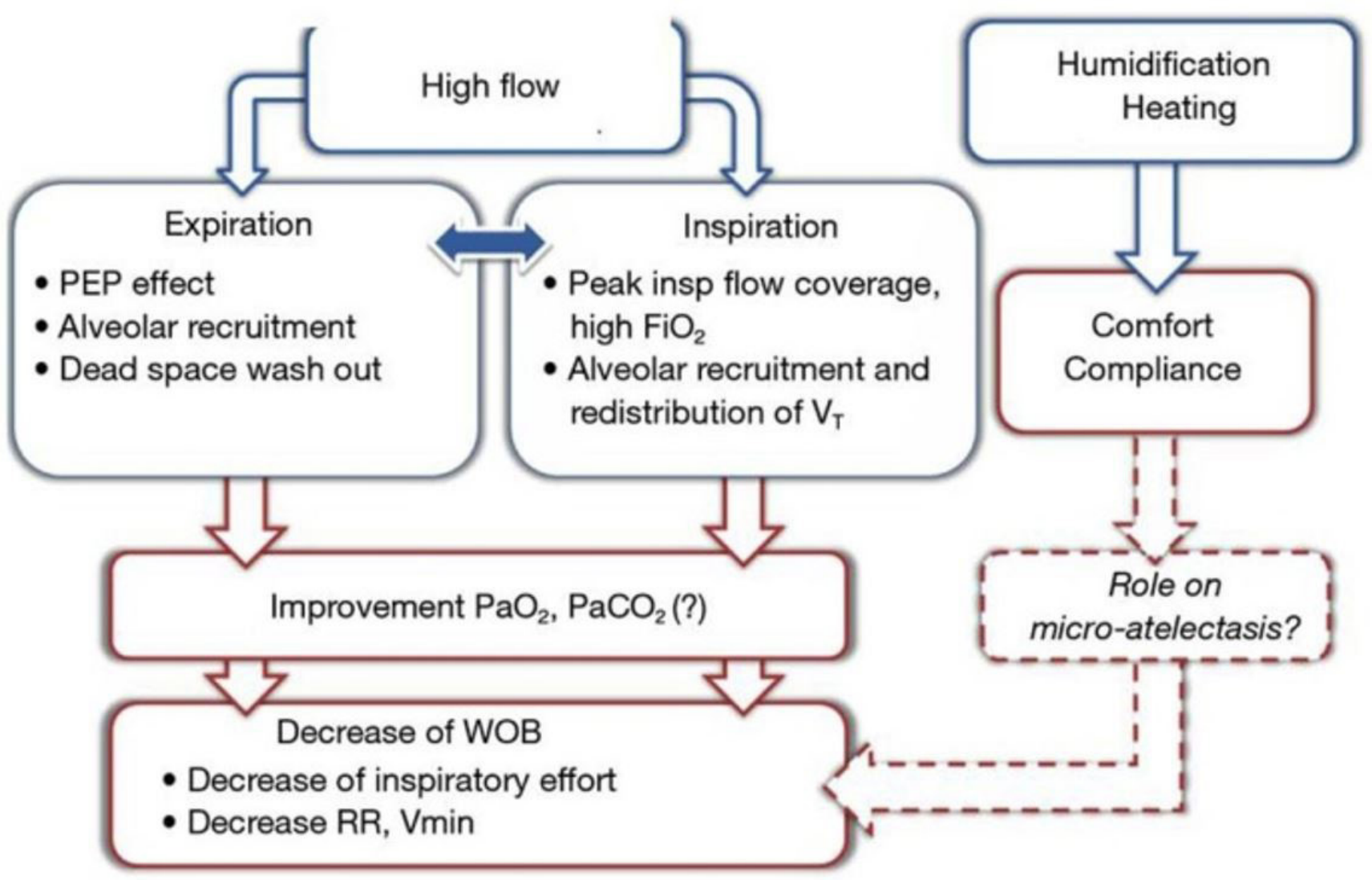

Cited From: Frat JP, Coudroy R, Marjanovic N, Thille AW. Ann Transl Med. 2017;5(14):297.

Figure 1. The working principle of HFNC. 
patients, but also causes dilution of oxygen concentration due to excessive air inhalation (Nishimura, 2016). The IFR achieved by HFNC can basically match the oxygen flow requirement of patients with respiratory failure, so that the volume fraction of inhaled oxygen is constant and reaches the patient's requirement (up to $90 \%$ of the volume fraction of inhaled oxygen can be achieved). HFNC can provide $21 \% \sim 100 \%$ oxygen concentration and up to $60 \mathrm{~L} / \mathrm{min}$ oxygen flow, which can meet the needs of patients with acute hypoxia (Gotera et al., 2013). The oxygen flow delivered is closer to or even exceeds the spontaneous inhalation of patients with respiratory failure. It keeps $\mathrm{FiO}_{2}$ relatively constant, the HFNC delivers gas through a continuous high flow rate, and the actual $\mathrm{FiO}_{2}$ measured is closer to the preset oxygen concentration.

\subsection{HFNC flushes the dead space of the respiratory tract}

Continuous HFNC can flush the carbon dioxide in the upper respiratory tract and reduce the reabsorption of carbon dioxide, but the role of HFNC in the treatment of hypercapnia caused by carbon dioxide retention has not been fully defined (Dysart et al., 2009). An in vitro study confirmed that HFNC could flush the dead space of the nasopharynx at a flow rate of $30 \mathrm{~L} / \mathrm{min}$ and increase the volume fraction of inhaled oxygen. Under the scouring effect of HFNC, the patient's partial pressure of carbon dioxide $\left(\mathrm{PaCO}_{2}\right)$ can be decreased, and the partial pressure of oxygen $\left(\mathrm{PaO}_{2}\right)$ rises to a certain saturation state; after the saturation is reached, the scouring effect disappears, indicating that the upper respiratory dead space has been basically washed away. In another randomized crossover study (Möller et al., 2017), Möller et al. used xenon $\left({ }^{81 \mathrm{~m}} \mathrm{Kr}\right)$ for scintigraphy in 10 volunteers with closed breath, $\mathrm{CO}_{2}$ volume maps and oximetry in 3 patients who underwent tracheotomy through nasal respiration. They sampled the carbon monoxide and oxygen in the trachea and measured the inhalation. It was confirmed that the exhaled breath in the upper respiratory tract by HFNC can extend below the soft palate, further reducing the dead space, and the $\mathrm{CO}_{2}$ clearance rate is directly related to the HFNC flow and treatment time.

\subsection{HFNC maintains mucociliary clearance functions}

HFNC can provide relatively accurate constant temperature and constant humidity gas for nasal high-flow humidification oxygen therapy, which meets the gas temperature and humidity of the respiratory tract under human physiological conditions, and reduces the influence of medical dry and cold gases on the mucociliary system and mucosal function of the upper and lower respiratory tract (Pillow et al., 2009). Compared with ordinary oxygen therapy, HFNC can provide a gas environment with an absolute humidity of $44 \mathrm{mg} / \mathrm{L}$, which is the same as the physiological condition of alveoli, which can increase mucociliary clearance and maintain the integrity of respiratory mucosal epithelial cells, prevent energy loss caused by heat and moisture exchange in the alveoli (Frat et al., 2013). It also prevents bronchoconstriction or bronchospasm caused by dry and cold air, which increases patient comfort and tolerance.

\subsection{HFNC reduces upper airway resistance and resistive work of breathing}

Inhalation of $500 \mathrm{~mL}$ of tidal volume and respiratory rate of 12 times/min during normal breathing requires $156 \mathrm{Cal} / \mathrm{min}$ of heat. HFNC can adjust the transport gas in the range of $31{ }^{\circ} \mathrm{C} \sim 37^{\circ} \mathrm{C}$. When heated to $37^{\circ} \mathrm{C}$, the transport gas can be humidified to $100 \%$ relative humidity, which can replace the humidification function of nasal mucosa, reduce the required heat consumption; at the same time, good warming and humidifying effect reduces the friction between the nasal cavity and the gas, as well as the gas and gas, and reduces the airflow resistance, effectively reduce the breathing work caused by this resistance, thereby reducing metabolic oxygen consumption (Dysart et al., 2009).

In addition, the nasopharynx exerts a certain resistance to the inspiratory flow. HFNC can mechanically expand the nasopharynx by generating CAPA, thereby reducing the inspiratory resistance; and the decrease in inspiratory resistance can further reduce the patient's respiratory work (Lu \& Zhang, 2018).

\section{Clinical application of HFNC}

In 2015, Frat et al. (Frat et al., 2015b) published a multicenter clinical study involving 310 patients with hypoxemia-type respiratory failure. Compared with conventional oxygen therapy and noninvasive positive pressure ventilation (NPPV), HNFC had similar endotracheal intubation rates, but the number of days without ventilator-assisted breathing increased within 28 days and the risk of death at 90 days decreased. This laid the foundation for HFNC in the treatment of hypoxic respiratory failure.

Patients with ARDS have acute respiratory distress and refractory type I respiratory failure as the main clinical manifestations. Relieving dyspnea and correcting hypoxia is an important strategy for ARDS treatment. Frat et al (Frat et al., 2015a) showed that HFNC, like NPPV, can significantly reduce respiratory rate, improve oxygen partial pressure, and HFNC is better tolerated. However, if the respiratory rate is still higher than 30 times/min after $1 \mathrm{~h}$ of treatment with HFNC, the risk of intubation is significantly increased.

Expert consensus on the application of clinical specifications for nasal high-flow humidification oxygenation (Respiratory Critical Care Medicine Group of Respiratory Medicine Branch of Chinese Medical Association, 2019): HFNC can be used as a first-line treatment for ARDS patients with mild hypoxemia (200 mm Hg $<\mathrm{PaO}_{2} / \mathrm{FiO}_{2} \leq 300 \mathrm{~mm} \mathrm{Hg}$ ) (level of evidence II, (OCEBM Levels of Evidence Working Group, 2016). The moderate hypoxemia without clear tracheal intubation (100 mm Hg $<\mathrm{PaO}_{2} / \mathrm{FiO}_{2} \leq 200 \mathrm{~mm} \mathrm{Hg}$ ) can be evaluated again after $1 \mathrm{~h}$ of treatment with HFNC. If symptoms do not improve, they should be changed to Non-invasive positive pressure ventilation (NPPV) or Invasive positive pressure ventilation (IPPV, level of evidence) II); ARDS with severe hypoxemia $\left(\mathrm{PaO}_{2} / \mathrm{FiO}_{2}<100 \mathrm{mmHg}\right)$ are not recommended for routine HFNC therapy (Level of Evidence III).

In patients with invasive mechanical ventilation, after evacuating the ventilator and removing the tracheal intubation, the respiratory 
function is often not fully recovered. The intubation rate is planned to be $6 \%$ to $23 \%$ within 48 to 72 hours after extubation (FrutosVivar et al., 2011), so NPPV is often required. For sequential treatment. Hernández et al (Hernández et al., 2016) confirmed that compared with NPPV, HFNC is not inferior to high-risk patients undergoing extubation in preventing respiratory failure after extubation and avoiding re-intubation, and HFNC has better comfort and tolerance, and fewer complications (Li et al., 2018).

In addition, for the treatment of tissue hypoxemia, studies have shown that (Ozturan et al., 2019; Tomruk et al., 2019) compared with conventional oxygen therapy, HFNC can significantly reduce the concentration of carboxyhemoglobin in the blood of patients with carbon monoxide poisoning, and shorten the time spent in the rescue room, so it is a promising treatment.

\subsection{Status of AHF respiratory support}

AHF is a serious threat to human health. In the United States alone, approximately 1 million patients are hospitalized each year due to AHF (Benjamin et al., 2018), and nearly $90 \%$ of AHF patients complain of dyspnea and most exhibit symptoms and signs of varying degrees of pulmonary congestion (Mebazaa et al., 2010).

The incidence of respiratory failure is between $5 \%$ and 13.9\% (Tomruk et al., 2019). Therefore, respiratory support is often one of the first treatments for AHF patients in emergency department. Respiratory support methods include oxygen therapy, non-invasive ventilation, and invasive mechanical ventilation, but so far, there is insufficient data to demonstrate which one is the ideal one for a better prognosis in AHF (Miller et al., 2019).

Oxygen therapy is one of the routine means of clinical treatment of dyspnea (including AHF patients). Many doctors and patients believe that oxygen can reduce dyspnea, improve myocardial tissue oxygenation and improve heart function. However, due to the lack of high-quality evidence, the role of oxygen therapy in the treatment of patients with AHF has been debated (Sepehrvand \& Ezekowitz, 2016). Although clinicians have reached a consensus on the treatment of acute hypoxemia, it is unclear whether oxygen therapy should be given in patients with normal blood oxygen saturation $\left(\mathrm{SpO}_{2}\right)$.

Physiological studies (Farquhar et al., 2009) have shown that hyperoxia stimulation overproduces oxygen radical reactions, induces vasoconstriction, reduces coronary blood flow, and ultimately leads to cardiac dysfunction, which is therefore harmful. Another study (Ezekowitz et al., 2012) showed that patients' perception of dyspnea was not directly related to $\mathrm{SpO}_{2}$.

In recent years, several influential randomized controlled trials have shown that oxygen therapy has no clinical benefit in patients with acute myocardial infarction without hypoxemia (Sepehrvand et al., 2018; Hofmann et al., 2017) and may even be harmful (Stub et al., 2015). Recent guidelines for heart failure (Ponikowski et al., 2016; Ezekowitz et al., 2017; Atherton et al., 2018; Chinese Society of Cardiology, 2018) suggest that oxygen therapy for patients with AHF must be cautious, and patients with AHF without hypoxemia should not be routinely treated with oxygen.
According to different clinical conditions, the corresponding oxygen therapy and oxygen therapy targets should be recommended separately.

Non-invasive ventilation can increase oxygenation and reduce work of breathing through positive airway pressure. Ventilation support further improves alveolar ventilation and reduces respiratory work and carbon dioxide levels. Compared with traditional oxygen therapy, non-invasive ventilation can improve dyspnea more quickly, correct acute respiratory failure, shorten the critical time of the disease, reduce the risk of endotracheal intubation, and possibly reduce the mortality of high-risk patients (Berbenetz et al., 2019). Therefore, most current guidelines (Ponikowski et al., 2016; Ezekowitz et al., 2017; Atherton et al., 2018; Chinese Society of Cardiology, 2018) recommend that non-invasive ventilation should be performed as soon as possible for patients with AHF who have respiratory distress (breathing frequency $>25$ beats $/ \mathrm{min}$ ) and hypoxemia (arterial oxygen saturation. $\mathrm{SaO}_{2}<94 \%$ or $\mathrm{SpO}_{2}<90 \%$ ) for respiratory support. If the condition continues to worsen after active treatment (disorder of consciousness, abnormal breathing rhythm, or respiratory rate $<8$ beats / min, spontaneous respiration weak or disappear, $\mathrm{PaCO}_{2}$ progressive elevation), intolerance of noninvasive ventilation or presence of noninvasive ventilation contraindications. It should be treated with tracheal intubation and invasive mechanical ventilation. HFNC can be used in patients who are not well tolerated with noninvasive positive pressure ventilation indications (Chinese Medical Doctor Association Emergency Physician Branch, Chinese Society of Cardiothoracic Anesthesia First Aid and Resuscitation Branch, 2017).

\subsection{Application Status of HFNC in AHF}

There are many similarities between HFNC and NPPV in the treatment principle, which are driven by electric turbines to form high-speed airflow. The flow control is realized by the solenoid valve, and the airflow is heated and humidified, which belongs to the positive pressure ventilation in the traditional sense. They are able to maintain a certain level of PEEP, open the airway, reduce dead space, improve ventilation, and allow air leaks in the open airway (Expert consensus on clinical application of adult nasal high-flow humidification oxygen therapy, 2019). Therefore, some scholars have classified HFNF as a type of non-invasive ventilation and applied it to AHF (Masip, 2019).

\subsection{Nasal high-flow humidification oxygen therapy improves dyspnea in patients with acute heart failure}

A controlled trial conducted by Makdee et al. (Makdee et al., 2017) in 128 patients with emergency cardiogenic pulmonary edema showed that compared with conventional oxygen therapy, after 60 minutes of treatment, HFNC can significantly reduce the average respiratory rate of patients and improve their dyspnea. In a prospective study of 44 patients with AHF, Carratalá et al. (Carratalá et al., 2018) also confirmed that patients treated with HFNC showed significant improvement in respiratory comfort, oxygenation index, and respiratory rate at 1,2 , and 24 hours compared with conventional oxygen therapy $(\mathrm{P}<0.05)$. 
Similar studies have been obtained in similar studies conducted in China (Zhang et al., 2019; An et al., 2018).

\subsection{HFNC improves hemodynamics in patients with AHF}

The CPAP effect brought by HFNC can change the hemodynamics of patients with heart failure. Roca et al (Roca et al., 2013) observed 10 patients with NYHA class III heart failure, measured the diameter of the inferior vena cava before and after HFNC, and set the flow rate to $20 \mathrm{~L} / \mathrm{min}$ and $40 \mathrm{~L} / \mathrm{min}$. The inferior vena cava collapse index was $20 \%$ and $53 \%$ lower than the baseline, respectively, and the change disappeared after evacuation. It can be speculated that HFNC can be used without affecting cardiac output.

It improves hemodynamic status in NYHA class III heart failure patients by producing positive intrathoracic pressure and reducing cardiac preload. Inata et al. (Inata \& Takeuchi, 2017) applied HFNC in the treatment of children with respiratory failure after congenital heart surgery in children, and found that HFNC can reduce the negative work of respiratory work and the large negative fluctuation of intrathoracic pressure, so that HFNC helps to reduce ventricular afterload, and thus improve hemodynamic status.

\subsection{Comparison of HNFC and non-invasive ventilation}

There is currently no high-quality controlled study of HFNC and non-invasive ventilation in patients with AHF. Previous studies (Carratalá Perales et al., 2011) reported that 5 patients with moderate (20\%) to severe (80\%) dyspnea in AHF patients had poor efficacy in non-invasive ventilation in the rescue room, switched to HFNC, patients with dyspnea and comfort were effective Improved, and after 24 hours of HFNC treatment, the patient's arterial $\mathrm{SpO}_{2}$ increased from $85 \%$ to $99 \%$.

Chinese scholar Yang et al (Yang et al., 2019) observed 52patients with AHF, HFNC and NPPV can significantly improve the patient's respiratory rate, heart rate, $\mathrm{PaO}_{2}, \mathrm{PaCO}_{2}$ and oxygenation index, the efficacy of the two was similar, and there was no difference in the rate of tracheal intubation due to treatment failure, but the comfort and tolerability of HFNC treatment was significantly better than that of NPPV. The results of a subgroup analysis of a multicenter clinical trial of HFNC and NPPV for acute decompensated heart failure in an emergency department by Haywood et al (Haywood et al., 2019) also confirmed that in patients with acute decompensated heart failure secondary to respiratory failure (no need for emergency tracheal intubation), HFNC is not inferior to NPPV.

\subsection{Comparison of HNFC and traditional oxygen therapy}

As mentioned above, HFNC not only provides highflow humidification, warmed oxygen, but also high comfort compared to conventional oxygen therapy; it also produces a certain positive airway pressure. Positive airway pressure can increase the intrathoracic pressure, reduce venous return, and reduce the preload, especially in patients with heart failure with reduced ejection fraction. On the other hand, the patient's inspiratory effort can be significantly reduced. Thereby, the pleural cavity negative pressure during inhalation is reduced, the left ventricular transmural pressure is decreased, and the afterload is correspondingly lowered.

At the same time, a certain level of PEEP can expand the trapped lung (alveoli), increase the capacity of the end-tidal lung, improve the lung compliance, move the water in the alveoli to the pulmonary interstitial, and promote the return of alveolar fluid and interstitial fluid into the vascular lumen, reduce extravascular lung water, increase functional residual capacity, prevent alveolar or small airway collapse, improve ventilation to blood flow imbalance, and increase oxygenation. Therefore, HFNC is a good alternative to traditional oxygen therapy in patients with mild to moderate hypoxemia. Rochwerg et al. (Rochwerg et al., 2019) pointed out through a meta-analysis of HFNC research in recent years that in patients with respiratory failure, although HFNC had no effect on mortality, HFNC reduced the need for invasive mechanical ventilation (RR $0.85,95 \%$ CI $0.74-0.99$ ) and a $4.4 \%$ reduction in absolute risk compared with conventional oxygen therapy. Zhu et al. (Zhu et al., 2017) further showed that compared with traditional oxygen therapy; HFNC reduces respiratory support upgrades and it can be safely used in patients after adult heart surgery.

\section{Indications for HNFC in AHF}

Although in a recent single-center retrospective study, Kang et al (Kang et al., 2019) concluded that HFNC has similar results in terms of increased $\mathrm{SpO}_{2}$ and in-hospital clinical outcomes for endotracheal intubation in patients with AHF, supporting HFNC as the first choice for oxygen therapy when AHF patient masks are still unable to relieve hypoxemia after oxygen inhalation, there is no uniform conclusion on the application of HFNC in AHF. Currently available reference guidelines for heart failure and HFNC application-related expert consensus are in patients with mild to moderate hypoxemia $\left(100 \mathrm{mmHg} \leq \mathrm{PaO}_{2} /\right.$ $\mathrm{FiO}_{2}<300 \mathrm{mmHg}$ ), no indication for emergency tracheal intubation and patients with relatively stable vital signs can try HFNC. Patients with mild ventilatory dysfunction $(\mathrm{pH} \geq 7.3)$ can also be used with caution. However, it should be prepared to replace it with non-invasive assisted ventilation or tracheal intubation/invasive positive pressure ventilation (level of evidence II). If HFNC fails or when the patient experiences respiratory distress (respiration rate $>25$ beats $/ \mathrm{min}, \mathrm{SpO}_{2}<90 \%$ ) or severe pulmonary edema and or hypoxemia progresses to respiratory failure $\left(\mathrm{PaO}_{2}<60 \mathrm{mmHg}, \mathrm{PaCO}_{2}>50 \mathrm{mmHg}\right)$ with acidosis $(\mathrm{pH}<7.35)$, it should be upgraded to non-invasive assisted ventilation or endotracheal intubation as appropriate (Expert consensus on clinical application of adult nasal high-flow humidification oxygen therapy, 2019).

\section{Conclusions}

HFNC has been successfully applied in several situations. However, the indications are not conclusive, with much of the proven benefit being subjective and physiologic. In patients with severe hypoxemic respiratory failure, it is suggested that HFNC is an alternative to other high-flow systems and noninvasive ventilation. Not all patients with respiratory failure are eligible for HFNC. Health care providers should consider whether to 
use HFNC based on factors such as the patient's condition and etiology. The PEEP effect of HFNC is significantly weaker than the CPAP effect produced by non-invasive ventilators, so the treatment of non-invasive ventilators is still better in patients with severe pulmonary edema. Strict monitoring is necessary for all patients using HFNC, including changes in heart rate, blood pressure, respiratory rate, and respiratory pattern. Intubation delays caused by neglected monitoring during HFNC use may result in a poor prognosis for the patient. HFNC has a unique advantage in the treatment of AHF with hypoxemia due to the ability to produce a certain level of PEEP, providing humidified warming and stable oxygen concentration and oxygen flow, reducing respiratory work and comfort. However, there is still a lack of standardized guidelines to guide the application, indications and contraindications are not clear, we need to be more and meticulous research to demonstrate its long-term use.

\section{Acknowledgements}

This study was supported by Promotion of Appropriate Techniques for Rural and Urban Community Health in Fujian Province (2019031).

\section{References}

An, Y.P., Luo, S.P., \& Yang, X.Z. (2018). Therapeutic effect of nasal highflow oxygen therapy on cardiogenic pulmonary edema. Journal of Clinical Emergency Call, 19(11), 762-764.

Anderson, N. J., Cassidy, P. E., Janssen, L. L., \& Dengel, D. R. (2006). Peak inspiratory flows of adults exercising at light, moderate and heavy workloads. Journal of the International Society for Respiratory Protection, 23, 53-63.

Atherton, J. J., Sindone, A., De Pasquale, C. G., Driscoll, A., MacDonald, P. S., Hopper, I., Kistler, P., Briffa, T. G., Wong, J., Abhayaratna, W. P., Thomas, L., Audehm, R., Newton, P. J., O'Loughlin, J., Connell, C., \& Branagan, M (2018). National heart foundation of australia and cardiac society of Australia and New Zealand: Australian clinical guidelines for the management of heart failure 2018. The Medical Journal of Australia, 209(8), 363-369. http://dx.doi.org/10.5694/ mja18.00647. PMid:30067937.

Benjamin, E. J., Virani, S. S., Callaway, C. W., Chamberlain, A. M., Chang, A. R., Cheng, S., Chiuve, S. E., Cushman, M., Delling, F. N., Deo, R., de Ferranti, S. D., Ferguson, J. F., Fornage, M., Gillespie, C., Isasi, C. R., Jiménez, M. C., Jordan, L. C., Judd, S. E., Lackland, D., Lichtman, J. H., Lisabeth, L., Liu, S., Longenecker, C. T., Lutsey, P. L., Mackey, J. S., Matchar, D. B., Matsushita, K., Mussolino, M. E., Nasir, K., O’Flaherty, M., Palaniappan, L. P., Pandey, A., Pandey, D. K., Reeves, M. J., Ritchey, M. D., Rodriguez, C. J., Roth, G. A., Rosamond, W. D., Sampson, U. K. A., Satou, G. M., Shah, S. H., Spartano, N. L., Tirschwell, D. L., Tsao, C. W., Voeks, J. H., Willey, J. Z., Wilkins, J. T., Wu, J. H., Alger, H. M., Wong, S. S., \& Muntner, P., and the American Heart Association Council on Epidemiology and Prevention Statistics Committee and Stroke Statistics Subcommittee (2018). Heart Disease and Stroke Statistics-2018 Update: A report from the american heart association. Circulation, 137(12), e67-e492. http://dx.doi.org/10.1161/CIR.0000000000000558. PMid:29386200.

Berbenetz, N., Wang, Y., Brown, J., Godfrey, C., Ahmad, M., Vital, F. M., Lambiase, P., Banerjee, A., Bakhai, A., \& Chong, M. (2019). Non-invasive positive pressure ventilation (CPAP or bilevel NPPV) for cardiogenic pulmonary oedema. Cochrane Database of Systematic Reviews, 4, CD005351. http://dx.doi.org/10.1002/14651858.CD005351.pub4. PMid:30950507.
Carratalá, J. M., Díaz Lobato, S., Brouzet, B., Más-Serrano, P., Espinosa, B., \& Llorens, P. (2018). Efficacy and safety of high-flow nasal cannula oxygen therapy in patients with acute heart failure. Emergencias, 30(6), 395-399. PMid:30638342.

Carratalá Perales, J. M., Llorens, P., Brouzet, B., Albert Jiménez, A. R., Fernández-Cañadas, J. M., Carbajosa Dalmau, J., Martínez Beloqui, E., \& Ramos Forner, S. (2011). High-Flow therapy via nasal cannula in acute heart failure. Revista Espanola de Cardiologia, 64(8), 723725. PMid:21497974.

Chinese Medical Doctor Association Emergency Physician Branch, Chinese Society of Cardiothoracic Anesthesia First Aid and Resuscitation Branch (2017). Emergency clinical practice guide for acute heart failure in China (2017). Chinese Journal of Emergency Medicine, 26(12), 1347-1357.

Chinese Society of Cardiology (2018). Guidelines for the diagnosis and treatment of heart failure in China 2018. Chinese Journal of Cardiology, 46(10), 760-789.

Corley, A., Caruana, L. R., Barnett, A. G., Tronstad, O., \& Fraser, J. F. (2011). Oxygen delivery through high-flow nasal cannulae increase end-expiratory lung volume and reduce respiratory rate in postcardiac surgical patients. British Journal of Anaesthesia, 107(6), 998-1004. http://dx.doi.org/10.1093/bja/aer265. PMid:21908497.

Dysart, K., Miller, T. L., Wolfson, M. R., \& Shaffer, T. H. (2009). Research in high flow therapy: mechanisms of action. Respiratory Medicine, 103(10), 1400-1405. http://dx.doi.org/10.1016/j.rmed.2009.04.007. PMid:19467849.

Ezekowitz, J. A., Hernandez, A. F., O'Connor, C. M., Starling, R. C., Proulx, G., Weiss, M. H., Bakal, J. A., Califf, R. M., McMurray, J. J., \& Armstrong, P. W. (2012). Assessment of dyspnea in acute decompensated heart failure: insights from ASCEND-HF (Acute Study of Clinical Effectiveness of Nesiritide in Decompensated Heart Failure) on the contributions of peak expiratory flow. Journal of the American College of Cardiology, 59(16), 1441-1448. http://dx.doi. org/10.1016/j.jacc.2011.11.061. PMid:22497823.

Ezekowitz, J. A., O’Meara, E., McDonald, M. A., Abrams, H., Chan, M., Ducharme, A., Giannetti, N., Grzeslo, A., Hamilton, P. G., Heckman, G. A., Howlett, J. G., Koshman, S. L., Lepage, S., McKelvie, R. S., Moe, G. W., Rajda, M., Swiggum, E., Virani, S. A., Zieroth, S., AlHesayen, A., Cohen-Solal, A., D’Astous, M., De, S., Estrella-Holder, E., Fremes, S., Green, L., Haddad, H., Harkness, K., Hernandez, A. F., Kouz, S., LeBlanc, M. H., Masoudi, F. A., Ross, H. J., Roussin, A., \& Sussex, B. (2017). 2017 Comprehensive Update of the Canadian Cardiovascular Society Guidelines for the Management of Heart Failure. The Canadian Journal of Cardiology, 33(11), 1342-1433. http://dx.doi.org/10.1016/j.cjca.2017.08.022. PMid:29111106.

Farquhar, H., Weatherall, M., Wijesinghe, M., Perrin, K., Ranchord, A., Simmonds, M., \& Beasley, R. (2009). Systematic review of studies of the effect of hyperoxia on coronary blood flow. American Heart Journal, 158(3), 371-377. http://dx.doi.org/10.1016/j.ahj.2009.05.037. PMid:19699859.

Frat, J. P., Brugiere, B., Ragot, S., Chatellier, D., Veinstein, A., Goudet, V., Coudroy, R., Petitpas, F., Robert, R., Thille, A. W., \& Girault, C. (2015a). Sequential application of oxygen therapy via high-flow nasal cannula and noninvasive ventilation in acute respiratory failure: an observational pilot study. Respiratory Care, 60(2), 170-178. http:// dx.doi.org/10.4187/respcare.03075. PMid:25294935.

Frat, J. P., Goudet, V., \& Girault, C. (2013). High flow, humidifiedreheated oxygen therapy: a new oxygenation technique for adults. Revue des Maladies Respiratoires, 30(8), 627-643. http://dx.doi. org/10.1016/j.rmr.2013.04.016. PMid:24182650.

Frat, J. P., Thille, A. W., Mercat, A., Girault, C., Ragot, S., Perbet, S., Prat, G., Boulain, T., Morawiec, E., Cottereau, A., Devaquet, J., Nseir, 
S., Razazi, K., Mira, J. P., Argaud, L., Chakarian, J. C., Ricard, J. D., Wittebole, X., Chevalier, S., Herbland, A., Fartoukh, M., Constantin, J. M., Tonnelier, J. M., Pierrot, M., Mathonnet, A., Béduneau, G., Delétage-Métreau, C., Richard, J. C., Brochard, L., Robert, R., FLORALI Study Group, \& REVA Network (2015b). High-flow oxygen through nasal cannula in acute hypoxemic respiratory failure. The New England Journal of Medicine, 372(23), 2185-2196. http://dx.doi. org/10.1056/NEJMoa1503326. PMid:25981908.

Frutos-Vivar, F., Esteban, A., Apezteguia, C., González, M., Arabi, Y., Restrepo, M. I., Gordo, F., Santos, C., Alhashemi, J. A., Pérez, F., Peñuelas, O., \& Anzueto, A. (2011). Outcome of reintubated patients after scheduled extubation. Journal of Critical Care, 26(5), 502-509. http://dx.doi.org/10.1016/j.jcrc.2010.12.015. PMid:21376523.

Gheorghiade, M., \& Pang, P. S. (2009). Acute heart failure syndromes. Journal of the American College of Cardiology, 53(7), 557-573. http:// dx.doi.org/10.1016/j.jacc.2008.10.041. PMid:19215829.

Gotera, C., Diaz Lobato, S., Pinto, T., \& Winck, J. C. (2013). Clinical evidence on high flow oxygen therapy and active humidification in adults. Revista Portuguesa de Pneumologia, 19(5), 217-227. http:// dx.doi.org/10.1016/j.rppneu.2013.03.005. PMid:23845744.

Groves, N., \& Tobin, A. (2007). High flow nasal oxygen generates positive airway pressure in adult volunteers. Australian Critical Care, 20(4), 126-131. http://dx.doi.org/10.1016/j.aucc.2007.08.001. PMid:17931878.

Haywood, S. T., Whittle, J. S., Volakis, L. I., Dungan, G. 2nd, Bublewicz, M., Kearney, J., Ashe, T., Miller, T. L., \& Doshi, P. (2019). HVNI vs NIPPV in the treatment of acute decompensated heart failure: Subgroup analysis of a multi-center trial in the ED. The American Journal of Emergency Medicine, 37(11), 2084-2090. http://dx.doi. org/10.1016/j.ajem.2019.03.002. PMid:30880040.

Hernández, G., Vaquero, C., Colinas, L., Cuena, R., González, P., Canabal, A., Sanchez, S., Rodriguez, M. L., Villasclaras, A., \& Fernández, R. (2016). Effect of Postextubation High-Flow Nasal Cannula vs Noninvasive Ventilation on Reintubation and Postextubation Respiratory Failure in High-Risk Patients: A Randomized Clinical Trial. Journal of the American Medical Association, 316(15), 15651574. http://dx.doi.org/10.1001/jama.2016.14194. PMid:27706464.

Hofmann, R., James, S. K., Jernberg, T., Lindahl, B., Erlinge, D., Witt, N., Arefalk, G., Frick, M., Alfredsson, J., Nilsson, L., Ravn-Fischer, A., Omerovic, E., Kellerth, T., Sparv, D., Ekelund, U., Linder, R., Ekström, M., Lauermann, J., Haaga, U., Pernow, J., Östlund, O., Herlitz, J., Svensson, L., \& DETO2X-SWEDEHEART Investigators (2017). Oxygen therapy in suspected acute myocardial infarction. The New England Journal of Medicine, 377(13), 1240-1249. http:// dx.doi.org/10.1056/NEJMoa1706222. PMid:28844200.

Inata, Y., \& Takeuchi, M. (2017). Complex effects of high-flow nasal cannula therapy on hemodynamics in the pediatric patient after cardiac surgery. Journal of Intensive Care, 5(1), 30. http://dx.doi. org/10.1186/s40560-017-0227-y. PMid:28572979.

Kang, M. G., Kim, K., Ju, S., Park, H. W., Lee, S. J., Koh, J. S., Hwang, S. J., Hwang, J. Y., Bae, J. S., Ahn, J. H., Jang, J. Y., Park, Y., Jeong, Y. H., Kwak, C. H., \& Park, J. R. (2019). Clinical efficacy of high-flow oxygen therapy through nasal cannula in patients with acute heart failure. Journal of Thoracic Disease, 11(2), 410-417. http://dx.doi. org/10.21037/jtd.2019.01.51. PMid:30962984.

Li LL, Dai B, Dong XX. (2018). Meta-analysis of the effect of transnasal high-flow oxygen therapy after removal of tracheal intubation. Chung-Hua Hu Li Tsa Chih, 53(12), 1492-1497.

Lu, W., \& Zhang, M. (2018). Clinical application of nasal high-flow oxygen therapy in critically ill and severe diseases. Chinese Journal of Emergency Medicine, 27(4), 446-450.
Makdee, O., Monsomboon, A., Surabenjawong, U., Praphruetkit, N., Chaisirin, W., Chakorn, T., Permpikul, C., Thiravit, P., \& Nakornchai, T. (2017). High-flow nasal cannula versus conventional oxygen therapy in emergency department patients with cardiogenic pulmonary edema: a randomized controlled trial. Annals of Emergency Medicine, 70(4), 465-472.e2. http:// dx.doi.org/10.1016/j.annemergmed.2017.03.028. PMid:28601264.

Masclans, J. R., \& Roca, O. (2012). High-flow oxygen therapy in acute respiratory failure. Clinical Pulmonary Medicine, 19(3), 127-130. http://dx.doi.org/10.1097/CPM.0b013e3182514f29.

Masip, J. (2019). Noninvasive ventilation in acute heart failure. Current Heart Failure Reports, 16(4), 89-97. http://dx.doi.org/10.1007/ s11897-019-00429-y. PMid:31147960.

Mebazaa, A., Pang, P. S., Tavares, M., Collins, S. P., Storrow, A. B., Laribi, S., Andre, S., Mark Courtney, D., Hasa, J., Spinar, J., Masip, J., Frank Peacock, W., Sliwa, K., Gayat, E., Filippatos, G., Cleland, J. G., \& Gheorghiade, M. (2010). The impact of early standard therapy on dyspnoea in patients with acute heart failure: the URGENTdyspnoea study. European Heart Journal, 31(7), 832-841. http:// dx.doi.org/10.1093/eurheartj/ehp458. PMid:19906690.

Mebazaa, A., Yilmaz, M. B., Levy, P., Ponikowski, P., Peacock, W. F., Laribi, S., Ristic, A. D., Lambrinou, E., Masip, J., Riley, J. P., McDonagh, T., Mueller, C., deFilippi, C., Harjola, V. P., Thiele, H., Piepoli, M. F., Metra, M., Maggioni, A., McMurray, J. J., Dickstein, K., Damman, K., Seferovic, P. M., Ruschitzka, F., Leite-Moreira, A. F., Bellou, A., Anker, S. D., \& Filippatos, G. (2015). Recommendations on pre-hospital and early hospital management of acute heart failure: a consensus paper from the Heart Failure Association of the European Society of Cardiology, the European Society of Emergency Medicine and the Society of Academic Emergency Medicine--short version. European Heart Journal, 36(30), 1958-1966. http://dx.doi.org/10.1093/eurheartj/ehv066. PMid:25998514.

Miller, P. E., van Diepen, S., \& Ahmad, T. (2019). Acute Decompensated Heart Failure Complicated by Respiratory Failure. Circulation: Heart Failure, 12(5), e006013. http://dx.doi.org/10.1161/ CIRCHEARTFAILURE.119.006013. PMid:31030542.

Möller W, Feng S, Domanski U, Franke KJ, Celik G, Bartenstein P, Becker S, Meyer G, Schmid O, Eickelberg O, Tatkov S, Nilius G. (2017) Nasal high flow reduces dead space. Journal of Applied Physiology, 122(1), 191-197.

Nishimura, M. (2016). High-flow nasal cannula oxygen therapy in adults: physiological benefits, indication, clinical benefits, and adverse effects. Respiratory Care, 61(4), 529-541. http://dx.doi.org/10.4187/ respcare.04577. PMid:27016353.

OCEBM Levels of Evidence Working Group. (2016). The Oxford 2011 Levels of Evidence. Oxford Centre for Evidence-Based Medicine; Retrieved from http://www.cebm.net/index.aspx?o=5653.

Ozturan, I. U., Yaka, E., Suner, S., Ozbek, A. E., Alyesil, C., Dogan, N. O., Yilmaz, S., \& Pekdemir, M. (2019). Determination of carboxyhemoglobin half-life in patients with carbon monoxide toxicity treated with high flow nasal cannula oxygen therapy. Clinical Toxicology, 57(7), 617-623. http://dx.doi.org/10.1080/15563650.20 18.1540046. PMid:30689450.

Parke, R., McGuinness, S., \& Eccleston, M. (2009). Nasal high-flow therapy delivers low level positive airway pressure. British Journal of Anaesthesia, 103(6), 886-890. http://dx.doi.org/10.1093/bja/ aep280. PMid:19846404.

Pillow, J. J., Hillman, N. H., Polglase, G. R., Moss, T. J., Kallapur, S. G., Cheah, F. C., Kramer, B. W., \& Jobe, A. H. (2009). Oxygen, temperature and humidity of inspired gases and their influences on airway and lung tissue in near-term lambs. Intensive Care Medicine, 35(12), 2157-2163. http://dx.doi.org/10.1007/s00134-009-1624-z. PMid:19756508. 
Ponikowski, P., Voors, A. A., Anker, S. D., Bueno, H., Cleland, J. G. F., Coats, A. J. S., Falk, V., González-Juanatey, J. R., Harjola, V. P., Jankowska, E. A., Jessup, M., Linde, C., Nihoyannopoulos, P., Parissis, J. T., Pieske, B., Riley, J. P., Rosano, G. M. C., Ruilope, L. M., Ruschitzka, F., Rutten, F. H., \& van der Meer, P., and the ESC Scientific Document Group (2016). 2016 ESC Guidelines for the diagnosis and treatment of acute and chronic heart failure: The Task Force for the diagnosis and treatment of acute and chronic heart failure of the European Society of Cardiology (ESC)Developed with the special contribution of the Heart Failure Association (HFA) of the ESC. European Heart Journal, 37(27), 2129-2200. http://dx.doi. org/10.1093/eurheartj/ehw128. PMid:27206819.

Respiratory Critical Care Medicine Group of Respiratory Medicine Branch of Chinese Medical Association, Critical Care Medicine Working Committee of Respiratory Medicine Branch of Chinese Medical Doctor Association. (2019). Expert consensus on clinical application of adult nasal high-flow humidification oxygen therapy. Chinese Journal of Tuberculosis and Respiratory Diseases, 42(2), 83-91.

Roca, O., Pérez-Terán, P., Masclans, J. R., Pérez, L., Galve, E., Evangelista, A., \& Rello, J. (2013). Patients with New York Heart Association class III heart failure may benefit with high flow nasal cannula supportive therapy: high flow nasal cannula in heart failure. Journal of Critical Care, 28(5), 741-746. http://dx.doi.org/10.1016/j.jcrc.2013.02.007. PMid:23602035.

Rochwerg, B., Granton, D., Wang, D. X., Helviz, Y., Einav, S., Frat, J. P., Mekontso-Dessap, A., Schreiber, A., Azoulay, E., Mercat, A., Demoule, A., Lemiale, V., Pesenti, A., Riviello, E. D., Mauri, T., Mancebo, J., Brochard, L., \& Burns, K. (2019). High flow nasal cannula compared with conventional oxygen therapy for acute hypoxemic respiratory failure: a systematic review and meta-analysis. Intensive Care Medicine, 45(5), 563-572. http://dx.doi.org/10.1007/ s00134-019-05590-5. PMid:30888444.
Sepehrvand, N., \& Ezekowitz, J. A. (2016). Oxygen Therapy in Patients With Acute Heart Failure: Friend or Foe. JACC. Heart Failure, 4(10), 783-790. http://dx.doi.org/10.1016/j.jchf.2016.03.026. PMid:27289409.

Sepehrvand, N., James, S. K., Stub, D., Khoshnood, A., Ezekowitz, J. A., \& Hofmann, R. (2018). Effects of supplemental oxygen therapy in patients with suspected acute myocardial infarction: a metaanalysis of randomised clinical trials. Heart (British Cardiac Society), 104(20), 1691-1698. http://dx.doi.org/10.1136/heartjnl-2018-313089. PMid:29599378.

Stub, D., Smith, K., Bernard, S., Nehme, Z., Stephenson, M., Bray, J. E., Cameron, P., Barger, B., Ellims, A. H., Taylor, A. J., Meredith, I. T., \& Kaye, D. M., and the AVOID Investigators (2015). Air versus oxygen in ST-Segment-Elevation Myocardial Infarction. Circulation, 131(24), 2143-2150. http://dx.doi.org/10.1161/ CIRCULATIONAHA.114.014494. PMid:26002889.

Tomruk, O., Karaman, K., Erdur, B., Armagan, H. H., Beceren, N. G., Oskay, A., \& Bircan, H. A. (2019). A New promising treatment strategy for carbon monoxide poisoning: high flow nasal cannula oxygen therapy. Medical Science Monitor, 25, 605-609. http://dx.doi. org/10.12659/MSM.914800. PMid:30663634.

Yang, J. W., Song, L. P., Han, P., \& Huang, H. X. (2019). Clinical analysis of nasal high-flow oxygen therapy for acute left heart failure. Beijing Medical Journal, 41(4), 258-262.

Zhang, K., Tian, F. E., Liu, J. G., Yang, S. Q., \& Yang, W. B. (2019). Clinical application of High-flow nasal cannula oxygen therapy in acute heart failure. Chinese Journal of Primary Medicine and Pharmacy, 26(5), 527-531.

Zhu, Y., Yin, H., Zhang, R., \& Wei, J. (2017). High-flow nasal cannula oxygen therapy vs conventional oxygen therapy in cardiac surgical patients: A meta-analysis. Journal of Critical Care, 38, 123-128. http:// dx.doi.org/10.1016/j.jcrc.2016.10.027. PMid:27886577. 